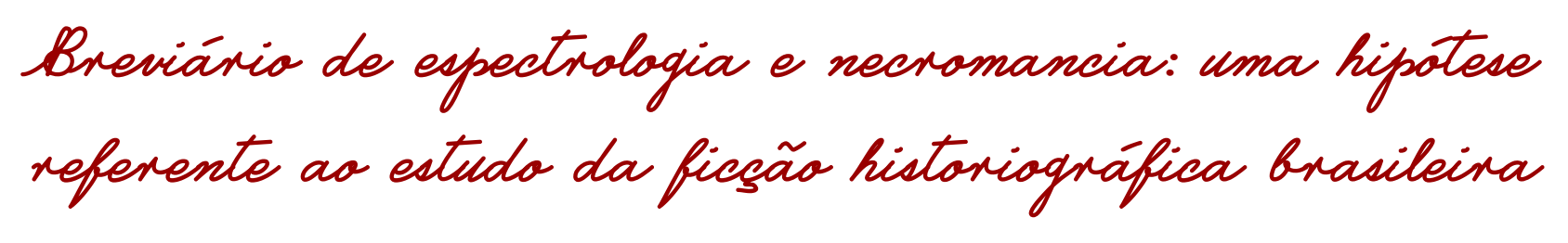

Marcos Vinícius Lima de Almeida ${ }^{1}$

"É um milagre: o instante em um átimo está aí, em um átimo já passou, antes um nada, depois um nada, retorna entretanto ainda como um fantasma e perturba a tranquilidade de um instante posterior." ${ }^{2}$

Friedrich Nietzsche, Segunda Consideração Intempestiva

NOSSOS PARAPSICÓLOGOS AVANÇARAM POUCO NO ESTUDO DE FAZENDAS MAL-ASSOMBRADAS. Falta no mercado um desses livros de capa verde-água plastificada com um título berrante e uma foto de orelha com um doutor PhD de cabelos brancos, formado num obscuro instituto polonês e versado na catalogação sistemática de assombrações. Somente um desses livros vendidos em feiras de necromancia - cujo olhar está voltado para as sombras -, pode arrancar as lascas mais profundas do inconsciente cultural e exibir sem rodeios o rosto transparente das assombrações das senzalas.

Esse livro imaginário conterá a foto de cada fazenda e comunidade onde um espectro arrastou suas correntes etéreas. Nosso pesquisador reunirá depoimentos dos quatro cantos do Brasil, passará noites mal dormidas em porões e ranchos, enquanto tem o sono velado por uma máquina capaz de captar a mínima variação ectoplasmática. Essa obra megalomaníaca deve ser lida e estudada sem qualquer ironia. Deve-se suspender totalmente a descrença: como um filólogo destrinchando as mais obscuras expressões do Apocalipse de João, com a paciência de quem lê os manuais de pesca em Moby Dick.

Nosso pesquisador trará no livro o relato de sonhos de crianças. E também daqueles jovens que acordaram no meio da noite com o estralar de chicotes na janela. É espantoso que esse PhD polonês ainda não tenha ao menos vislumbrado sua obra-prima. Esse livro que ele não escreveu é seu futuro: o maior fantasma de sua vida. Somente um olhar sem razão pode despertar a simpatia dos espíritos, ouvir o eco das vozes dos sem nome que vagam sem descanso pelas ruínas da barbárie.

\footnotetext{
${ }^{1}$ Mestrando em Literatura e Crítica Literária na PUCSP. Membro do grupo de pesquisa "O narrador e as fronteiras do relato”. O presente ensaio faz parte de um projeto maior, financiado pela Fapesp (processo: 16/04695-1) sob orientação da Prof. Dra Annita Costa Malufe, que trata do problema da ficção histórica na literatura brasileira contemporânea.

2 Tradução de Marco Antônio Casanova. Grifos nossos.
} 
Recuará a todo custo àquele lugar onde a palavra não se descolou da magia. Só assim ele pode assumir a perspectiva dos espectros. Verá mulheres em transe, arranhando paredes com a voz gutural. E praticará o pecado imperdoável de ouvir aquilo que os mortos sem sepultura têm a dizer. Nosso necromante libertará legiões de almas penadas. Um sem número de espectros. Lembrando-se deles. Deixando-os falar.

Somente nesses detritos da história cultural, nas zonas mais obscuras do misticismo, da bruxaria e da necromancia o historiador pode escutar a vibração silenciosa das pancadas da barbárie através dos séculos. Como aqueles caçadores primitivos, rosto colado ao chão, rastreando as pegadas de uma besta no deserto. Foram eles os primeiros narradores, conjecturando narrativas a partir de indícios esparsos, como diz Carlo Ginzburg 3 , mas eram também adivinhos: olhando para o passado como quem prevê o futuro.

A escrita da história e a relação com passado estão desde sempre ligadas aos rituais fúnebres, afirma Jeanne-Marie Gagnebin. ${ }^{4}$ Em grego, signo (séma) é túmulo. O poeta, guardião da memória, liberta os antepassados das águas sombrias do rio do esquecimento absoluto. Mas aqueles que não puderam ser enterrados tampouco podem ser esquecidos: estão desde sempre condenados a vagar por aí. Pois o passado que não é devidamente lembrado, enterrado, também não pode ser esquecido: mortos sem sepultura, assombram o nosso presente e assombrarão todo e qualquer porvir. Esse passado espectral recalcado voltará metamorfoseado como sintoma. ${ }^{5} \mathrm{~A}$ verdadeira escrita da história digna desse nome não é outra coisa senão um rito de sepultamento. ${ }^{6}$ Diálogo, mas principalmente escuta desses fantasmas sem nome, a vagar sem descanso sob a tempestade dos séculos, figuras errantes na paisagem que "acumula ruína sobre ruína", testemunhas espectrais da barbárie.

$* * *$

As vozes dos mortos, aqueles que viveram antes de nós, e dos vivos, aqueles que habitam o presente, estão juntas, num coral fúnebre, porque os mortos continuam espectralmente a habitar o presente. E o que de fato se acumula, inexoravelmente, no decorrer da história, são mais e mais

\footnotetext{
${ }^{3}$ GINZBURG, Carlo. Sinais: Raízes de um paradigma indiciário In: Mitos, emblemas, sinais: morfologia e história. Tradução: Federico Carotti. São Paulo: Companhia das Letras, 1989. p. 151.

${ }^{4}$ GAGNEBIN, Jeanne-Marie. Prólogo: Escrita, Morte, Transmissão. In: Limiar, aura e rememoração: ensaios sobre Walter Benjamin. São Paulo: Editora 34, 2014. p. 13.

5 "É possível afirmar que todo agrupamento social padece, de alguma forma, dos efeitos de sua própria inconsciência. São 'inconscientes', em uma sociedade, tanto as passagens de sua história relegadas ao esquecimento - por efeito de proibições explícitas ou de jogos de conveniência não declarados - quanto as demandas silenciadas de minorias cujos anseios não encontram meios de se expressar. Excluído das possibilidades de simbolização, o mal-estar silenciado acaba por se manifestar em atos que devem ser decifrados, de maneira análoga aos sintomas dos que buscam a clínica psicanalítica." KELL, Maria Rita. Tortura e sintoma social. In: SAFATLE, Vladimir et al. O que resta da ditadura: a exceção brasileira. São Paulo: Boitempo Editorial, 2010. p. 124-125

${ }^{6}$ CERTEAU, Michel de. O lugar do morto e o lugar do leitor In: A escrita da História. Tradução de Maria de Lourdes Menezes. Rio de Janeiro: Forense, 1982. p. 106.

${ }^{7}$ BENJAMIN, Walter. Sobre o conceito da história. In: Obras escolhidas vol.I: Magia e técnica, arte e politica: ensaios sobre literatura e história da cultura. Trad. Sérgio Paulo Rouanet. 8a ed. São Paulo. Brasiliense, 2012.
} 
mortos. A carga espectral dos presentes futuros (assim como número de túmulos num cemitério) tende necessariamente a inchar, ressaltando o caráter essencialmente necromante da história: "De fato", afirma Paul Ricoeur (2007, p. 376, grifo nosso), "de que modo poderíamos negligenciar o simples fato de que, na história, só se lida com os mortos de outrora?”. A ficção histórica, que não é outra coisa senão a Literatura e a ficção operando no horizonte da história, necessariamente assume essa premissa de dialogar com os mortos: pois a metáfora do espectro é um gesto de evocação dos mortos. ${ }^{8}$

Esse livro imaginário sobre senzalas mal-assombradas possivelmente poderia servir de epígrafe a uma futura obra que tentasse ler os índices da nossa época em retrospecto. Haveria um capítulo de abertura sobre um presidente que abandonou o palácio do governo citando histórias de fantasmas. ${ }^{9}$ Conduzido pela obra, o leitor encontraria citações de Hamlet e Marx. ${ }^{10} \mathrm{O}$ tempo está fora dos eixos. Um espectro ronda a Europa, um espectro assombra o reino da Dinamarca. Há algo de podre no ar. "Lembra de mim", diz o espectro, ao se despedir de um príncipe incrédulo. ${ }^{11}$ Mas esse príncipe silencioso logo passa da incredulidade à obstinação. Arma seu ardil: escreve uma ficção, uma espécie de ratoeira, e captura seu inimigo.

\footnotetext{
${ }^{8}$ ASSMANN, Aleida. Espaços da recordação: formas e transformações da memória cultural. Campinas, SP: Editora da Unicamp, 2011, p. 188

9 'Deve ter fantasma lá', disse Temer a Joesley sobre o Alvorada. Estadão. Blog do Fausto Macedo. 19 Maio 2017. Disponível em: http://politica.estadao.com.br/blogs/fausto-macedo/deve-ter-fantasma-la-disse-temer-a-joesleysobre-o-alvorada/ Acesso: 03/10/2017.

${ }^{10}$ DERRIDA, Jacques. Espectros de Marx: o estado da divida, o trabalho do luto e a nova Internacional. Trad. Anamaria Skinner. Rio de Janeiro: Relume-Dumará, 1994.

${ }^{11}$ SHAKESPEARE, William. Hamlet. Tradução: Lawrence Flores Pereira. São Paulo: Penguin Companhia, 2015.
} 


\section{Referências bibliagráficas}

ASSMANN, Aleida. Espaços da recordação: formas e transformações da memória cultural. Tradução de Paulo Soethe, et al Campinas, SP: Editora da Unicamp, 2011.

BENJAMIN, Walter. Sobre o conceito da história. In: .Obras escolhidas, vol.I: Magia e técnica, arte e política: ensaios sobre literatura e história da cultura. Tradução de Sérgio Paulo Rouanet. $8^{a}$ ed. São Paulo. Brasiliense, 2012.

CERTEAU, Michel de. A escrita da História. Tradução de Maria de Lourdes Menezes. Rio de Janeiro: Forense, 1982. p. 106.

DERRIDA, Jacques. Espectros de Marx: o estado da divida, o trabalho do luto e a nova Internacional. Trad. Anamaria Skinner. Rio de Janeiro: Relume-Dumará, 1994.

GAGNEBIN, Jeanne-Marie. Limiar, aura e rememoração: ensaios sobre Walter Benjamin. São Paulo: Editora 34, 2014.

GINZBURG, Carlo. Mitos, emblemas, sinais: morfologia e história. Tradução de Federico Carotti. São Paulo: Companhia das Letras, 1989.

KELL, Maria Rita. Tortura e sintoma social. In: SAFATLE, Vladimir et al. O que resta da ditadura: a exceção brasileira. São Paulo: Boitempo Editorial, 2010. p. 124-125

RICOEUR, Paul. A memória, a história, o esquecimento. Tradução de Alain François et al. Campinas, SP: Editora da Unicamp, 2007.

SHAKESPEARE, William. Hamlet. Tradução: Lawrence Flores Pereira. São Paulo: Penguin Companhia, 2015. 